\title{
KARAKTERISASI VOLUME KALIBRATOR ALAT PENAKAR CURAH HUJAN MENGGUNAKAN METODE GRAVIMETRI
}

\section{Volume Characterization of Rain Gauge Calibrator by Gravimetric Method}

\author{
Diina Qiyaman M, Bernadus H. Sirenden, Tatik Maftukhah, dan Nur Tjahyo Eka \\ Pusat Penelitian Metrologi, Lembaga IImu Pengetahuan Indonesia Kompleks Puspitek Gedung 420 Setu, \\ Tangerang Selatan, Indonesia \\ e-mail:diinaqiyaman@gmail.com
}

Diterima: 10 Januari 2018, Direvisi: 25 Januari 2018, Disetujui: 29 Januari 2018

\begin{abstract}
Abstrak
Badan Meteorologi, Klimatologi, dan Geofisika (BMKG) memiliki alat ukur curah hujan yang tersebar di 180 lokasi stasiun pemantau cuaca di seluruh daerah Indonesia. Alat ukur ini perlu dikalibrasi secara berkala untuk menjamin hasil pengukuran dan ketertelusurannya. Tim peneliti Puslit Metrologi LIPI bekerjasama dengan BMKG mengembangkan kalibrator curah hujan yang dapat dibawa dan mudah untuk digunakan. Karakterisasi dilakukan pada kalibrator ini sebagai jaminan hasil pengukuran dan pengujian untuk memenuhi standar. Karakterisasi dilakukan dengan metode gravimetri menggunakan timbangan mengacu pada prosedur kalibrasi Laboratorium Volume Puslit Metrologi LIPI. Kecepatan aliran air diatur dengan pompa dalam satuan Pulse Width Modulation (PWM), dan parameter - parameter pengukuran ditampilkan pada aplikasi di dalam komputer. Telah dilakukan pengambilan data untuk karakterisasi kalibrator curah hujan dengan hasil volume rata - rata pada kondisi standar $\left(20^{\circ} \mathrm{C}\right)$ sebesar $970 \mathrm{ml}, 966 \mathrm{ml}$, dan $971 \mathrm{ml}$ pada $P W M$ pompa 100, 150, dan 255. Ketidakpastian bentangan yang didapat sebesar $3 \mathrm{ml}$. Dari hasil karakterisasi dan simulasi perhitungan didapat ketidakpastian bentangan sebesar $1 \%$ untuk curah hujan di atas $18 \mathrm{~mm}$. Hasil tersebut memenuhi standar ketidakpastian maksimal pengukuran curah hujan sebesar $2 \%$ untuk kadar curah hujan $0-500 \mathrm{~mm}$.
\end{abstract}

Kata Kunci: karakterisasi, kalibrator curah hujan, volume, metode gravimetri, aliran.

\begin{abstract}
Meteorological, Climatological, and Geophysical Agency (BMKG) has hundreds of rain gauges located in 180 weather stations around Indonesia teritory. These rain gauges are needed to be calibrated periodically to ensure its traceability and measurement result. Research team from RCM LIPI collaborating with BMKG have developed a portable and easy-to-use rain gauge calibrator. The calibrator is characterized to ensure its traceability and as a qualification test. Characterization is processed by gravimetric method using an electronic balance referring to calibration procedure of Volume Laboratory in RCM LIPI. Flow velocity is regulated by small pump in PWM units, and the other measurement parameters is showed on an application in personal computer. The results of average volume in standard condition $\left(20^{\circ} \mathrm{C}\right)$ are $970 \mathrm{ml}, 966 \mathrm{ml}$, and $971 \mathrm{ml}$ for PWM 100, 150, and 255 respectively. The expanded uncertainty is $3 \mathrm{ml}$. From the characterization result and simulation of uncertainty calculation, expanded uncertainty of $1 \%$ is obtained. This value meets the requirement standard for rainfall, maximum $2 \%$ for rainfall between 0 and $500 \mathrm{~mm}$.
\end{abstract}

Keywords: characterization, rainfall calibrator, volume, gravimetric method, flow.

\section{PENDAHULUAN}

Curah hujan merupakan salah satu parameter lingkungan yang penting dan dibutuhkan di berbagai sektor kehidupan. Di sektor pertanian, informasi curah hujan menentukan jenis tanaman yang baik untuk ditanam dalam suatu periode (Runtunuwu \& Syahbuddin, 2007). Di sektor tata kota dan wilayah, informasi curah hujan dijadikan pertimbangan pemilihan lokasi dan tata letak suatu kota, daerah mana yang cocok dijadikan pemukiman, resapan air, lahan pertanian, perkantoran, maupun kebutuhan lokasi lainnya
(Wibowo, 2006). Di sektor transportasi seperti penerbangan, informasi ini digunakan untuk keselamatan penumpang di perjalanan (Pramono, 2013).

Badan Meteorologi, Klimatologi, dan Geofisika (BMKG) adalah lembaga negara yang menyediakan informasi terkait kondisi cuaca di Indonesia, termasuk jumlah curah hujan di setiap daerah. BMKG memiliki alat ukur curah hujan yang tersebar di seluruh daerah di Indonesia. Alat ini dikalibrasi secara berkala untuk menjamin kebenaran hasil pengukurannya. Kalibrasi dilakukan pada peralatan yang belum terpasang 
di lapangan dan untuk alat yang sudah terpasang di lapangan. Sebelum dipasang, kalibrasi dilakukan di laboratorium, dan apabila sudah dipasang, kalibrasi dilakukan secara insitu.

Kalibrasi dilakukan secara berkala setiap tiga sampai empat bulan. Saat ini alat pengukur curah hujan yang tersebar di berbagai daerah di Indonesia dikalibrasi oleh Layanan Satu Atap BMKG, yang berlokasi di Jakarta Pusat. Keterbatasan jumlah kalibrator menjadi kendala bagi BMKG untuk melakukan kalibrasi di stasiunstasiun pemantau cuaca yang jumlahnya mencapai 180 lokasi (BMKG, 2017). Kalibrator curah hujan ini juga masih perlu ditelusur kepada standar Satuan Internasional (SI) untuk menjamin hasil pengukurannya.

Tim peneliti Puslit Metrologi LIPI telah membuat kalibrator curah hujan yang dapat dibawa (portable) dan mudah digunakan untuk mendukung ketertelusuran pengukuran curah hujan di Indonesia. Tujuan dari penelitian ini adalah untuk validasi dan karakterisasi pada kalibrator curah hujan yang telah dibuat. Pada tulisan ini akan dijelaskan proses karakterisasi volume pada kalibrator curah hujan yang telah dibuat untuk jaminan hasil pengukuran dan pengujian hasilnya terhadap standar pengukuran yang sudah ditetapkan oleh WMO (WMO, 2008). Karakterisasi dilakukan di Laboratorium Volume Puslit Metrologi LIPI.

\section{TINJAUAN PUSTAKA}

\subsection{Alat Penakar Curah Hujan}

Curah hujan adalah peristiwa turunnya titik-titik air atau kristal-kristal es dari awan sampai ke permukaan tanah. Alat yang digunakan untuk mengukur jumlah curah hujan pada suatu daerah disebut alat penakar hujan. Satuan yang biasa digunakan untuk menghitung curah hujan adalah milimeter $(\mathrm{mm}) .1 \mathrm{~mm}$ curah hujan artinya tertampungnya air setinggi $1 \mathrm{~mm}$ pada suatu daerah datar seluas 1 meter persegi, setara dengan $1000 \mathrm{ml}$ atau 1 liter air (Achmadi, Setiawan, \& Sumardi, 2000).

Alat penakar curah hujan yang banyak digunakan di Indonesia dan memiliki kemampuan pengukuran yang tidak jauh berbeda adalah Tipping Bucket, Hellmann, dan Observatorium (Maftukhah dkk, 2016). Gambar 1 menunjukkan alat penakar hujan tipe Tipping Bucket atau cawan berjungkit. Pada tipe Tipping Bucket air hujan masuk melalui corong dan diterima oleh penakar curah hujan berbentuk kerucut. Penakar ini akan berjungkit ke bawah ketika sudah penuh dan mengalirkan air yang tertampung ke tabung penampung di bawahnya. Satu jungkitan tercatat 12 pada recorder sebagai satu pulsa dan dikonversi ke dalam satuan curah hujan. Penakar hujan tipe ini dapat bekerja otomatis mencatat jumlah curah hujan yang tertampung (Hendayana, n.d.).

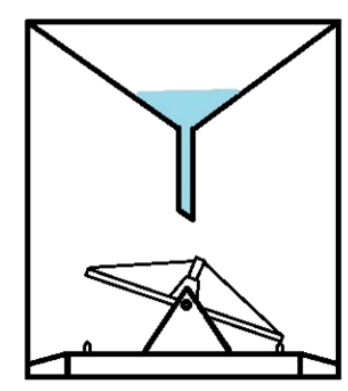

Gambar 1 Alat penakar curah hujan tipe Tipping Bucket.

Gambar 2(a) dan 2(b) adalah alat penakar curah hujan tipe Hellmann dan tipe Observatorium. Pada penelitian ini, kalibrator curah hujan yang dibuat hanya bisa digunakan untuk kalibrasi alat penakar curah hujan tipe Tipping Bucket sebagai alat penakar curah hujan yang paling banyak digunakan oleh BMKG.

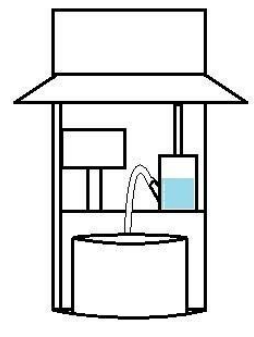

(a)

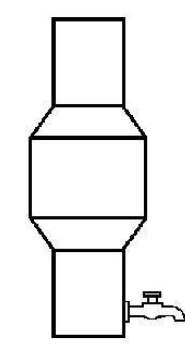

(b)
Gambar 2 Alat Penakar Curah Hujan (a) Tipe Hellmann (b) Tipe Observatorium.

\subsection{Kalibrator Alat Penakar Curah Hujan}

Beberapa penelitian tentang kalibrasi alat penakar curah hujan tipe Tipping Bucket telah dilakukan dengan metode yang berbeda oleh All Weather Inc, Waterlog, John Gorman, Molini, Iserloh, dan Aidin Pasarkhoo. Metode kalibrasi All Weather Inc menggunakan botol plastik yang berisi air dan dipasang di atas Tipping Bucket, dan dilakukan perhitungan jumlah jungkit secara manual (All Weather Inc, 2008). Metode kalibrasi Waterlog menggunakan botol berisi $198 \mathrm{ml}$ air yang dialirkan melalui Tipping Bucket. Air yang sudah melewati Tipping Bucket ditampung di dalam dua buah gelas ukur kapasitas $250 \mathrm{ml}$. Sistem kalibrasi ini menggunakan alat yang ringan dan kecil, tetapi manual dalam perhitungannya (Waterlog Series, 2017).

Metode kalibrasi yang dikembangkan oleh John Gorman menggunakan beberapa 
tabung yang berisi air yang ekivalen dengan curah hujan 20-50mm. Tabung ini dilengkapi dengan kendali untuk pengaturan laju aliran (Gorman, 2011). Penelitian Molini adalah membuat kalibrator curah hujan yang menghasilkan aliran fluida konstan. Aliran fluida dihasilkan dari tangki level konstan yang diatur ketinggiannya menggunakan aktuator mekanik, serta tiga buah katup solenoid yang dipasangi nozzle dengan ukuran berbeda-beda (Molini dkk, 2004).

Gustari membuat klasifikasi curah hujan untuk menentukan rentang ukur pengujian, yang terdiri dari kategori: tidak hujan, hujan ringan, hujan sedang, hujan lebat, dan hujan sangat lebat (Gustari dkk, 2012). Penelitian Iserloh adalah mengembangkan simulasi hujan yang portable untuk mendapatkan karakteristik curah hujan (Iserloh dkk, 2013). Aidin Parsakhoo melakukan kalibrasi terhadap simulasi curah hujan menggunakan alat ukur curah hujan (Pasarkhoo dkk, 2012).

Kalibrator alat penakar curah hujan didesain oleh Tim peneliti Puslit Metrologi LIPI seperti pada Gambar 3. Kalibrator ini berupa tabung penakar berkapasitas sekitar 1 liter yang dapat menghasilkan aliran fluida konstan untuk menyerupai kondisi tetesan hujan. Kecepatan aliran fluida diatur dengan menggunakan pompa yang terletak di bagian bawah tabung. Kecepatan pompa diatur oleh sebuah kendali mikroelektronik menggunakan satuan PWM (Pulse Width Modulation).

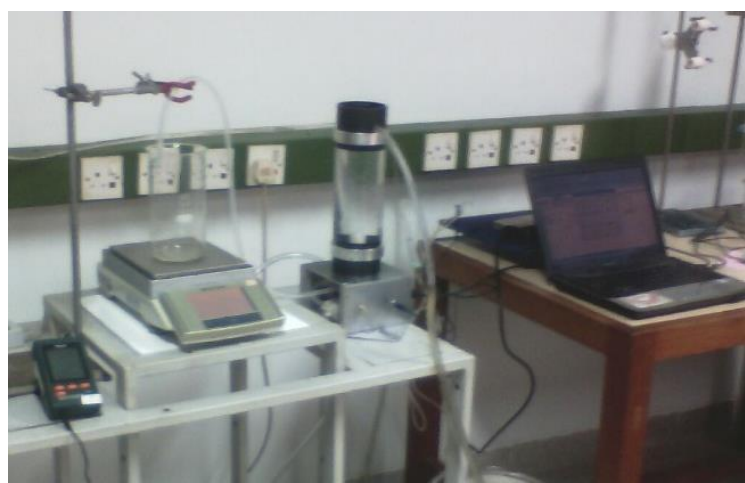

Gambar 3 Kalibrator alat penakar curah hujan.

Kendali mikro yang digunakan adalah Arduino Nano yang menerima dan mengirim data dari komputer pribadi. Sebuah aplikasi pada komputer telah dibuat untuk memudahkan operator alat untuk menentukan intensitas curah hujan yang diinginkan (Wijonarko dkk, 2017). Kalibrator ini juga dilengkapi dengan sensor temperatur dan kelembaban udara.

Kebaruan yang disampaikan pada tulisan ini ada pada kemampuan kalibrator curah hujan yang dapat melakukan pencatatan data secara otomatis dalam satu siklus dengan menggunakan software dan kemampuan untuk mengatur kecepatan aliran curah hujan yang ingin dikalibrasi. Karakterisasi volume dilakukan sebagai validasi untuk memastikan bahwa kalibrator curah hujan yang telah dibuat memenuhi persyaratan spesifikasinya.

Karakterisasi volume dilakukan dengan metode gravimetri, yaitu dengan mengukur massa aliran fluida yang melewati alat ukur dan ditampung di sebuah tangki penampung. Tangki penampung ini diletakkan di atas timbangan agar dapat langsung diukur massanya. Pembacaan nilai dapat dilakukan dengan dua metode, yaitu standing start-finish dan flying start-finish. Standing start-finish atau uji awal-dan-akhir diam adalah pembacaan pada kondisi aliran cairan diam. Flying start-finish atau uji awal-dan-akhir berjalan adalah pembacaan pada kondisi aliran berjalan. Pada proses kalibrasi ini, metode yang dipakai adalah standing start-finish, karena volume kalibrator yang akan digunakan hanya pada 1 nilai yaitu pada volume sekitar 1 liter.

\subsection{Model Matematik}

Penentuan volume dalam kalibrator didasarkan pada hukum kekekalan laju aliran massa, yaitu perubahan massa air pada kalibrator $\left(\Delta m_{p}\right)$ yang didorong oleh pompa melalui selang dan disalurkan ke tangki penampung sama dengan perubahan massa air yang ditampung dalam tangki penampung $\left(\Delta m_{c}\right)$.

$\Delta m_{p}=\Delta m_{c}$

Perubahan massa di dalam kalibrator berhubungan dengan perubahan volume air $\left(\Delta V_{p}\right)$ dikalikan dengan densitas air yang mengalir pada selang dan tangki penampung $\left(\rho_{\mathrm{a}}\right)$ sehingga untuk menghitung volume dasar dalam kalibrator dapat digunakan formula:

$\Delta V_{p}=\frac{\Delta m_{c}}{\rho_{a}}$

Perubahan massa air di dalam tangki penampung diketahui dengan mengurangkan nilai massa akhir $\left(m_{2}\right)$ dengan massa awal $\left(m_{1}\right)$. Penimbangan dilakukan dengan timbangan yang kinerjanya dipengaruhi oleh densitas udara $\left(\rho_{u}\right)$, densitas air $\left(\rho_{a}\right)$, dan densitas anak timbangan yang digunakan untuk mengkalibrasi timbangan $\left(\rho_{b}\right)$, sehingga untuk menghitung nilai massa air sebenarnya (true mass) digunakan formula berikut : 
$\Delta m_{c}=\left(m_{2}-m_{1}\right) \cdot \frac{\left(1-\frac{\rho_{u}}{\rho_{p}}\right)}{\left(1-\frac{\rho_{u}}{\rho_{a}}\right)}$

Densitas udara dihitung dari temperatur udara $\left(T_{u}\right)$, tekanan udara $\left(P_{u}\right)$, dan kelembaban udara $(\mathrm{RH})$ yang diukur selama pengambilan data, menggunakan pendekatan berikut (ISO/TR 20461:2000) :

$\rho_{u}=\frac{k_{1} P_{u}+R H\left(k_{2} T_{u}+k_{g}\right)}{T_{u}+T_{u}}$

Dimana :

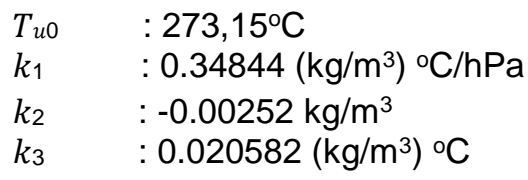

Densitas air $\left(\rho_{a}\right)$ dihitung dari temperatur air $\left(T_{a}\right)$ yang berada di dalam tangki penampung

$\rho_{a}=a_{5}\left(1-\frac{\left(T_{a}+a_{1}\right)^{2}\left(T_{a}+a_{2}\right)}{a_{2}\left(T_{a}+a_{4}\right)}\right)$

dimana :

$$
\begin{array}{ll}
a_{1} & :(-3,983035 \pm 0.00067){ }^{\circ} \mathrm{C} \\
a_{2} & : 301,797{ }^{\circ} \mathrm{C} \\
a_{3} & : 522528,9{ }^{\circ} \mathrm{C} \\
a_{4} & : 69,34881^{\circ} \mathrm{C} \\
a_{5} & :(999,974950 \pm 0.00084) \mathrm{kg} / \mathrm{m}^{3}
\end{array}
$$

Volume dasar $\left(\Delta V_{p}\right)$ yang didapat pada persamaan (2) adalah nilai pada kondisi aktual pengukuran. Karena kondisi aktual pengukuran dapat berbeda, nilai volume yang dilaporkan adalah nilai volume dasar pada kondisi standar $\left(20^{\circ} \mathrm{C}\right)$. Konversi $\Delta V_{p}$ menjadi $\Delta V_{p 20}$ dihitung dengan formula berikut :

$\Delta V_{p 20}=\Delta V_{p}\left[1-\alpha_{c}\left(T_{a}-20^{\circ} \mathrm{C}\right)\right]$

Karena pengukuran dilakukan sebanyak $n$ kali, nilai yang dilaporkan adalah nilai rata rata volume dasar yang dihitung dengan formula berikut :

$\overline{\Delta V_{p 20}}=\frac{\sum_{i=1}^{n} \Delta V_{p i}}{n}$

$\Delta V_{p 20}$ adalah nilai volume dasar pada kondisi standar $\left(20^{\circ} \mathrm{C}\right)$ yang dilaporkan.

\subsection{Komponen Ketidakpastian}

Menurut dokumen Vocabulary In Metrology, ketidakpastian adalah "parameter tidak negatif yang mencirikan sebaran nilai - nilai yang dianggap mewakili besaran yang diukur, berdasarkan informasi yang digunakan (JCGM, 2008). Terdapat beberapa komponen ketidakpastian yang perlu diperhatikan pada pengukuran ini, yaitu ketidakpastian yang berasal dari perhitungan atau tipe $A$, dan ketidakpastian yang berasal dari sertifikat kalibrasi atau tipe $B$.

\subsubsection{Ketidakpastian Tipe A}

Ketidakpastian tipe $\mathrm{A}$ adalah ketidakpastian yang dihitung secara statistik., biasanya berasal dari pengulangan pengukuran. Pada kalibrasi ini, komponen ketidakpastian dihitung dari standar deviasi hasil pengambilan 10 kali data pengukuran.

$u_{A}\left(\overline{\Delta V_{p 20}}\right)=\sqrt{\frac{\sum_{i=1}^{n}\left(\Delta V_{p s o i}-\overline{\Delta V_{p s o}}\right)^{2}}{n(n-1)}}$

\subsubsection{KetidakpastianTipe B}

Ketidakpastian tipe B adalah nilai ketidakpastian dari sertifikat kalibrasi. Pada kalibrasi ini, ketidakpastian tipe $\mathrm{B}$ bersumber dari sertifikat kalibrasi alat ukur temperatur air $\left(T_{a}\right)$, temperatur udara $\left(T_{u}\right)$, tekanan udara $\left(P_{u}\right)$, kelembaban relatif $(\mathrm{RH})$, timbangan, dan ketidakpastian densitas anak timbangan.

Ketidakpastian tipe B dihitung dengan formula berikut :

$u_{B}=\sqrt{\Sigma\left(\frac{U_{\text {cert }}}{k} \cdot c\right)^{2}}$

dimana $U_{\text {cert }}$ adalah ketidakpastian dari sertifikat kalibrasi, $\mathrm{k}$ adalah faktor cakupan, dan $\mathrm{c}$ adalah koefisien sensitivitas.

\subsubsection{Ketidakpastian Bentangan}

Dari nilai ketidakpastian tipe $A$ dan $B$ dihitung ketidakpastian gabungannya dengan formula berikut :

$u_{e}=\sqrt{u_{A}^{2}+u_{B}^{2}}$

Ketidakpastian bentangan dihitung dari nilai ketidakpastian gabungan dikalikan dengan faktor cakupan pada level kepercayaan 95\% ( $\left.k_{95}\right)$

$U_{e}=k_{95} \cdot u_{e}$ 


\section{METODE PENELITIAN}

Karakterisasi volume dilakukan di Laboratorium Volume Puslit Metrologi LIPI. Pengukuran dilakukan mengacu pada ISO 11631:1998 dan ISO/TR 5168:1998. Timbangan yang digunakan adalah timbangan elektronik tipe XS6002S dengan nomor seri 1128431308, memiliki resolusi 0,01 gram dan ketidakpastian 0,02 gram. Timbangan yang digunakan tertelusur ke Laboratorium Massa Puslit Metrologi LIPI.

Posisi kalibrator dan pompa diusahakan sedekat mungkin untuk meminimalisir panjang selang penyalur air. Volume air yang tertahan di dalam selang dianggap sangat kecil sehingga dapat diabaikan. Perlu diperhatikan juga agar tidak ada gelembung udara baik di dalam kalibrator maupun di dalam selang penyalur. Air aquades di dalam kalibrator curah hujan dialirkan dengan dorongan sebuah pompa yang terletak di bagian dasar kalibrator, melalui selang ke dalam tangki penampung. Kecepatan aliran diatur dengan dengan aplikasi komputer pada tiga titik ukur, yaitu PWM 100, 150, dan 255. Ketiga titik ukur ini dipilih sesuai dengan titik ukur yang biasa digunakan pada alat penakar curah hujan milik BMKG.

Pengambilan data dilakukan sebanyak 10 kali pada setiap titik ukurnya. Pencatatan nilai dilakukan dengan metode standing start-finish. Diagram skematik alat pada proses kalibrasi dapat dilihat pada Gambar 4. Penunjukkan timbangan dicatat pada kondisi awal saat tangki penampung masih kosong $\left(m_{1}\right)$, dan di akhir saat tangki penampung sudah berisi air yang dipindahkan dari dalam kalibrator $\left(m_{2}\right)$.

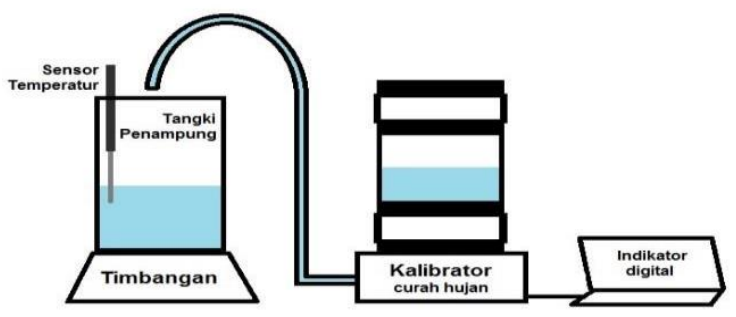

Gambar 4 Diagram skematik pengukuran.

Temperatur air di dalam tangki penampung diukur pada setiap awal dan akhir pengukuran $\left(T_{a}\right)$. Kondisi ruang pengukuran (temperatur udara, kelembaban relatif, dan tekanan udara) juga dicatat di awal dan akhir setiap pengulangan pengukuran. Persyaratan kondisi ruangan saat dilakukan kalibrasi adalah pada temperatur $(21,0-26,0)^{\circ} \mathrm{C}$ dengan variasi tidak lebih dari $\pm 2,0^{\circ} \mathrm{C}$ per jam.

\section{HASIL DAN PEMBAHASAN}

Karakterisasi volume dilakukan pada kondisi ruangan laboratorium dengan tekanan sebesar $(1004,5 \pm 2,3) \mathrm{hPa}$, temperatur $(20,1 \pm 0,9)^{\circ} \mathrm{C}$, dan kelembaban relatif $(55,3 \pm 1,8) \%$. Nilai rata rata setiap parameter pengukuran yang digunakan dalam perhitungan dapat dilihat pada Tabel 1. Massa terukur sebesar 970,12, 966,05, dan 971,50 gram pada PWM 100, 150, dan 255. Volume standar $\left(\mathrm{V}_{\mathrm{p} 20}\right)$ terhitung sebesar 970, 966, dan $971 \mathrm{ml}$ untuk titik ukur PWM 100, 150, dan 255 secara berurutan. Perbedaan kecepatan aliran karena pengaturan PWM pompa menyebabkan perbedaan hasil pengukuran volume. Hal ini disebabkan karena keterbatasan sistem untuk melakukan pembacaan data pada kecepatan aliran yang berbeda.

Tabel 1 Data pengukuran.

\begin{tabular}{ccccccccc}
\hline PWM & $\begin{array}{c}\Delta \mathbf{m} \\
(\mathbf{g r a m})\end{array}$ & $\begin{array}{c}\text { Temp. } \\
\text { air }\left({ }^{\circ} \mathbf{C}\right)\end{array}$ & $\begin{array}{c}\text { Densitas Air } \\
\left(\mathbf{g} / \mathbf{c m}^{3}\right)\end{array}$ & $\begin{array}{c}\text { Temp. } \\
\left({ }^{\circ} \mathbf{C}\right)\end{array}$ & $\begin{array}{c}\text { Press. } \\
(\mathbf{h P a})\end{array}$ & $\begin{array}{c}\text { Humid. } \\
(\%)\end{array}$ & $\begin{array}{c}\text { Densitas } \\
\text { udara } \\
\left(\mathbf{g} / \mathbf{c m}^{3}\right)\end{array}$ & $\begin{array}{c}\boldsymbol{V}_{p 20} \\
(\mathbf{m l})\end{array}$ \\
\hline 100 & 970,12 & 20,7 & 1,0016 & 20,1 & 1004,85 & 55,7 & 0,0012 & 970 \\
150 & $966 ., 05$ & 20,2 & 1,0016 & 20,1 & 1005,28 & 54,7 & 0,0012 & 966 \\
255 & 971,50 & 19,5 & 1,0014 & 19,5 & 1006,01 & 54,6 & 0,0012 & 971 \\
\hline
\end{tabular}

Perhitungan budget ketidakpastian dapat dilihat pada Tabel 2. Dapat terlihat bahwa komponen ketidakpastian terbesar berasal dari tipe $A$, yaitu karena pengulangan pengukuran. Hal ini disebabkan karena tangki penampung terbuka dan bersentuhan langsung dengan udara luar sehingga ada faktor penguapan air (Prakosa, Darmayanti, Sirenden, \& Hafid, 2015). Komponen ketidakpastian dari sertifikat atau tipe $B$ bernilai sangat kecil sehingga tidak 
berpengaruh signifikan terhadap ketidakpastian bentangannya. Ketidakpastian terbesar didapat pada titik ukur PWM 255 sebesar $3 \mathrm{ml}$ atau $0,29 \%$.

Tabel 2 Budget Ketidakpastian.

\begin{tabular}{llllllllll}
\hline PWM Pompa & $V_{p 20}(\mathbf{m l})$ & $\begin{array}{l}u_{A} \\
(\mathbf{m l})\end{array}$ & & $\begin{array}{l}u_{B} \\
(\mathbf{m l})\end{array}$ & $\mathbf{k}$ & $\mathbf{v}$ & $U_{\varepsilon}$ & \\
& & $(\mathbf{m l})$ & $(\%)$ & & & & $(\mathbf{m l})$ & $(\%)$ \\
\hline 100 & 970 & 1 & 0,09 & $2.23 \times 10^{-5}$ & 2,3 & 9 & 2 & 0,20 \\
150 & 966 & 1 & 0,08 & $2.22 \times 10^{-5}$ & 2,3 & 9 & 2 & 0,18 \\
255 & 971 & 1 & 0,13 & $2.22 \times 10^{-5}$ & 2,3 & 9 & 3 & 0,29 \\
\hline
\end{tabular}

Dengan budget ketidakpastian bentangan kalibrator sebesar $3 \mathrm{ml}$, dibuat simulasi perhitungan ketidakpastian kalibrasi alat penakar hujan tipe Tipping Bucket. Komponen yang diperhitungkan adalah ketidakpastian dari alat ukur diameter Tipping Bucket. Jika digabungkan, didapat perhitungan ketidakpastian bentangan alat penakar curah hujan seperti pada Tabel 3. Dari Tabel 3 dapat dilihat bahwa total ketidakpastian bentangan sebesar $1 \%$ untuk curah hujan di atas $18 \mathrm{~mm}$. Persyaratan dari WMO untuk ketidakpastian pengukuran curah hujan pada 0 - $500 \mathrm{~mm}$ adalah maksimal sebesar 2\%. Hasil ketidakpastian dari karakterisasi volume kalibrator yang dilakukan lebih kecil dari persyaratan, sehingga dapat dikatakan hasil validasi sudah cukup memenuhi persyaratan kalibrasi alat ukur curah hujan.

Tabel 3 Simulasi perhitungan ketidakpastian curah hujan.

\begin{tabular}{llcc}
\hline \multicolumn{1}{c}{ Ketidakpastian Pengukuran } & & \\
\hline No & Sumber & Nilai & Satuan \\
1 & Volume Standar & 3 & $\mathrm{ml}$ \\
$2 \quad$ Alat Ukur Diameter TB (simulasi) & 16 & $\mu \mathrm{m}$ \\
\hline $\begin{array}{l}\text { Simulasi Ketidakpastian Tipe B untuk Curah Hujan > 18 } \mathbf{m m} \\
\begin{array}{l}\text { Spesifikasi WMO untuk Ketidakpastian Pengukuran Curah Hujan (0-500) } \\
\text { mm }\end{array}\end{array}$ & $\mathbf{1}$ & $\%$ \\
\hline
\end{tabular}

\section{KESIMPULAN}

Validasi dan karakterisasi telah dilakukan pada kalibrator alat penakar curah hujan yang dibuat oleh Tim peneliti Puslit Metrologi LIPI. Dari hasil karakterisasi didapatkan volume kalibrator pada kondisi standar $\left(V_{p 20}\right)$ di PWM 100, 150, dan 255 sebesar 970, 966, dan $971 \mathrm{ml}$. Ketidakpastian bentangan terbesar dari pengukuran ini sebesar $3 \mathrm{ml}$. Dari simulasi perhitungan, didapat nilai ketidakpastian sebesar $1 \%$ untuk pengukuran curah hujan. Hasil validasi tersebut sudah memenuhi persyaratan spesifikasi teknis ketidak pastian curah hujan yang ditetapkan oleh WMO sebesar maksimal 2\% untuk curah hujan $0-500$ $\mathrm{mm}$. Pada proses validasi ini uji coba dilakukan di laboratorium sehingga masih perlu penelitian lebih lanjut untuk menguji performanya di lapangan.
Dengan dilakukannya karakterisasi ini diharapkan ketertelusuran alat penakar curah hujan di Indonesia dapat tersambung sehingga hasil pengukuran curah hujan yang dilakukan dapat lebih terjamin kebenarannya. Kalibrator alat penakar curah hujan yang sudah dikarakterisasi ini bermanfaat untuk mempermudah kalibrasi alat penakar hujan milik BMKG yang terdapat di stasiun cuaca di seluruh daerah di Indonesia.

\section{UCAPAN TERIMA KASIH}

Penulis mengucapkan terimakasih kepada manajemen Puslit Metrologi LIPI dan Program Riset Unggulan LIPI yang telah mendukung dan mendanai kegiatan penelitian dengan judul "Pembuatan Sistem Pengukur Mawar Hujan dan Kalibrator Curah Hujan Portabel yang Tertelusur 
ke SNSU". Terima kasih juga kepada BMKG atas kerjasamanya selama pelaksanaan penelitian ini.

\section{DAFTAR PUSTAKA}

Achmadi, S., Setiawan, I., \& Sumardi. (2000). Penakar Curah Hujan Otomatis Dengan Data Logger SD/MMC Berbasis SMS (Short Message Service ) (pp. 1-9). Semarang.

Aidin Parsakhoo, et al. (2012). Calibration of A Portable Single Nozzle Rainfall Simulator for Soil Erodibility Study in Hyrcanian Forests. African Journal of Agricultural Research, 7(27), 3957-3963.

All Weather Inc, National Drive (2008). Tipping Bucket Rain Gauge Models 6011-A and 6011B. Retrieved from http://www.allweatherinc.com/wpcontent/uploads/6011-0011.pdf. 2015

BMKG. (2017). Alamat Stasiun dan UPT BMKG | BMKG. Retrieved from http://www.bmkg.go.id/profil/stasiunupt.b $\mathrm{mkg}$.

Gorman, John. (2011). Introduction to The Tipping Bucket Rain Gauge. Retrieved from

https://www.wmo.int/pages/prog/www/IM OP/TrainingMat/2011-

Melbourne/Doc_3_3_Tipping-bucketrain-gauge_JGorman.pdf.

Gustari, I., Hadi, T.W., Hadi, S., Renggono, F. (2012). Akurasi Prediksi Curah Hujan Harian Operasional Di Jabodetabek : Perbandingan Dengan Model WRF. Jurnal Meteorologi dan Geofisika, 13(2), $119-130$.

Hendayana, D. (n.d.). Mengenal Nama dan Fungsi Alat - Alat Pemantau Cuaca dan Iklim. Retrieved from https://dhkangmas.files.wordpress.com/2 $01 \quad 1 / 06 /$ mengenal-nama-dan-alatdeteksicuaca-dan-iklim.pdf

International Standard. (1998). Measurement of Fluid Flow - Methods of Specifying Flowmeter Performance.ISO 11631:1998

International Standard. (1998). Measurement of Fluid Flow - Procedures for The Evaluation of Uncertainties.ISO/TR 5168 : 1998

JCGM. (2008). JCGM 200: 2008 International vocabulary of metrology - Basic and general concepts and associated terms. BIPM (Vol. 3). Retrieved from http://www.bipm.org/utils/common/docum en ts/jcgm/JCGM_200_2008.pdf

Maftukhah, T., Wijonarko, S., \& Rustandi, D. (2016). Comparison and Correlation among Measurement Results of Observatory, Hellmann, and Tipping

Molini A., Cassini G., Lanza L.G., Stagi L.(2004). Dealing with Uncertainty in Rainfall Gauges Calibration: The QM-RIM Metrological Validation. Retrieved from

https://www.wmo.int/pages/prog/www/IMOP/inter comparisons/RISept2004/Uncertainty_DI AM.pdf.

Prakosa, J. A., Darmayanti, E., Sirenden, B. H., \& Hafid. (2015). Volume Measurement of Piston Prover Cylinder by Gravimetric

Method for Validation of Water Flow Rate Traceability at Metrology LIPI. In J. Holub (Ed.), XXI IMEKO World Congress "Measurement in Research and Industry." Prague. http://doi.org/10.1002/adsc.200700568

Pramono, A. (2013). Aspek Hukum Keselamatan Penerbangan. Masalah - Masalah Hukum, 42(4), 601-608.

Runtunuwu, E., \& Syahbuddin, H. (2007). Perubahan Pola Curah Hujan dan Dampaknya Terhadap Periode Masa Tanam. Jurnal Tanah Dan Iklim, 26, 112.

T. Eserloh, et al. (2013). European Small Portable Rainfall Simulators: A Comparison of Rainfall Characteristics. CATENA-01978, 13.

Technical Report. (2000). Determination of Uncertainty for Volume Measurement Made Using the Gravimetric Method. ISO/TR 20461 : 2000

WaterLog Series. (2017). H-340-CalKit Tipping Bucket Rain Gauge Calibration Kit. Retrieved from https://www.waterlog.com/media/pdfs/h3 40-calkit-instructions.pdf

Wibowo, M. (2006). Model Penentuan Kawasan Resapan Air untuk Perencanaan Tata Ruang Berwawasan Lingkungan. Hidrosfir, 1(1), 1-7.

Wijonarko S., Maftukhah T., Rustandi D., Sirenden, B. H., Prakosa, J.A., Sediono, W., Darma, Y., Sukanda, R., Pinandito, M.

WMO. (2008). Guide to Meteorological Instruments and Methods of observation. Guide to Meteorological Instruments and Methods of Observation (Vol. I \& II). http://doi.org/Guide to meteorological instrument and observing practices 
